\title{
A!
}

This is an electronic reprint of the original article.

This reprint may differ from the original in pagination and typographic detail.

Nakamura, Kimihiro; Li, Qiang Qiang; Krejčí, Ondřej; Foster, Adam S.; Sun, Kewei; Kawai, Shigeki; Ito, Shingo

\section{On-Surface Synthesis of a m-Extended Diaza[8]circulene}

Published in:

Journal of the American Chemical Society

DOI:

10.1021/jacs.0c02534

Published: 15/05/2020

Document Version

Peer reviewed version

Please cite the original version:

Nakamura, K., Li, Q. Q., Krejí, O., Foster, A. S., Sun, K., Kawai, S., \& Ito, S. (2020). On-Surface Synthesis of a Extended Diaza[8]circulene. Journal of the American Chemical Society, 142(26), 11363-11369.

https://doi.org/10.1021/jacs.0c02534

This material is protected by copyright and other intellectual property rights, and duplication or sale of all or part of any of the repository collections is not permitted, except that material may be duplicated by you for your research use or educational purposes in electronic or print form. You must obtain permission for any other use. Electronic or print copies may not be offered, whether for sale or otherwise to anyone who is not an authorised user. 


\title{
On-Surface Synthesis of a $\pi$-Extended Diaza[8]circulene
}

\author{
Kimihiro Nakamura, ${ }^{\perp}$ Qiang-QiangLi, ${ }^{\perp}$ Ondřej Krejčí, Adam S. Foster,* Kewei Sun, \\ Shigeki Kawai,* and Shingo Ito*
}

\begin{abstract}
Heterocyclic[8]circulenes are an important class of polycyclic aromatic hydrocarbon molecules because of their 5 unique structural properties and promising applications. However, the synthesis of hetero[8]circulenes is still limited and thus is an 6 important synthetic challenge. Here we describe the first example of a $\pi$-extended diaza[8]circulene bearing six hexagons and two 7 pentagons, which was successfully synthesized only by a combined in-solution and on-surface synthetic strategy. State-of-the-art 8 scanning tunneling microscopy with a CO-functionalized tip and density functional theory calculations revealed its planar 9 conformation and unique electronic structure.
\end{abstract}

[8]Circulene (1) (Figure 1) is a polycyclic aromatic hydrocarbon (PAH) molecule in which the central octagon is

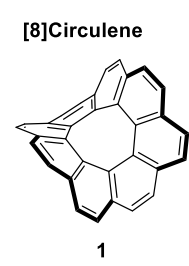

Saddle-shape

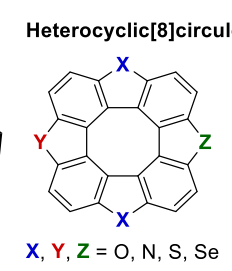

$\mathrm{X}, \mathrm{Y}, \mathrm{Z}=\mathrm{O}, \mathrm{N}, \mathrm{S}, \mathrm{Se}$

2

(Quasi-)Planar

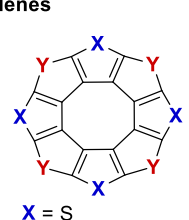

$\mathrm{Y}=\mathrm{Si}, \mathrm{Ge}, \mathrm{S}, \mathrm{S}$

3
This Work

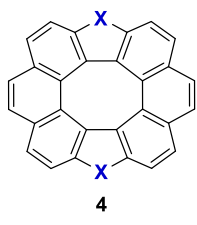

What shape?
Figure 1. [8]Circulene and heterocyclic [8]circulenes.

surrounded by and fused with eight benzene rings. Because of the high strain caused by the large sum of the wedge angles $\left(480^{\circ}\right),{ }^{1}$ [8]circulene has a saddle-shaped structure and is expected to be used as a building block in bottom-up synthesis of negatively curved (nano)graphenes. ${ }^{2}$ Nevertheless, the synthesis of [8] circulene ${ }^{3}$ as well as its benzo-fused derivatives ${ }^{4}$ was achieved quite recently.

Heterocyclic [8]circulenes are [8]circulene molecules in which one or more of the benzene ring(s) are replaced by heteroarene $\operatorname{ring}(\mathrm{s})$ such as pyrrole or furan (Figure 1). ${ }^{1,5}$ They exhibit unique properties compared with the parent [8]circulene (1) and have received much attention because of their promising applications in organic semiconductors, ${ }^{6,7}$ organic light-emitting diodes, ${ }^{8}$ and liquid-crystalline materials. ${ }^{9}$ However, the variety of the core structure of heterocyclic [8]circulenes is still limited. Notable examples synthesized to date include compounds 2 bearing four hexagons (benzenes) and four pentagons (heteroles) ${ }^{8-10}$ and compounds 3 bearing eight pentagons. ${ }^{6,11}$ Their structural feature is their planar or quasi-planar ${ }^{10 f, g}$ structure due to the smaller sums of the wedge angles derived from pentagons. A key research target is the synthesis and structure of heterocyclic [8]circulenes having other combinations of hexagons and pentagons. Thus, we were interested in designing and synthesizing diaza[8]circulene 4, which would be the first example of a heterocyclic [8]circulene bearing six hexagons (benzenes) and two pentagons (heteroles).

The development of polycyclic aromatic azomethine ylides $^{12,13}$ offers new pathways to nitrogen-containing PAHs. This 1,3-dipolar cycloaddition strategy enables the rapid construction of highly fused pyrrole structures and has been applied to the efficient synthesis of a variety of hithertounknown pyrrole-fused PAH molecules having planar $^{12,13 \mathrm{~b}-\mathrm{d}}$ and bowl ${ }^{14}$ shapes as well as antiaromatic molecules. ${ }^{15}$ In order to construct core structures with even more varied shapes and , we employ on-surface synthesis, which has recently emerged as a powerful tool for the bottom-up synthesis of nanocarbon structures, ${ }^{16}$ as exemplified by graphene nanoribbons, ${ }^{17}$ carbon nanotubes, ${ }^{18}$ fullerenes, ${ }^{19}$ acenes, ${ }^{20}$ periacenes, ${ }^{21}$ and isomeric nanographenes. ${ }^{22}$ On-surface synthesis also provides an effective approach toward heteroatomcontaining PAH molecules. ${ }^{15,23}$ Here we report a combined in-solution and on-surface synthesis of $\pi$-extended diaza[8]circulene 4 bearing six hexagons and two pentagons. In particular, the final cyclodehydrogenation of a precursor molecule could be achieved only by on-surface synthesis on a $\mathrm{Au}(111)$ surface, as all of the other solution-based reaction attempts failed. Therefore, we developed a straightforward and effective method for the synthesis of $\pi$-extended diaza[8]circulene $\mathbf{4}$ and studied its conformation, unique electronic structure, and intrinsic properties.

First, dibenzo[a,e]cyclooctatetraene (5) (Scheme 1) was reacted with azomethine ylides formed from iminium salts $\mathbf{6}$. Although cycloadducts 7 can be isolated, ${ }^{24}$ the obtained crude mixtures were directly oxidized with 2,3-dichloro-5,6-dicyano-

Received: March 4, 2020 
Scheme 1. Synthetic Route to $\pi$-Extended Diaza $[8]$ circulene 4a

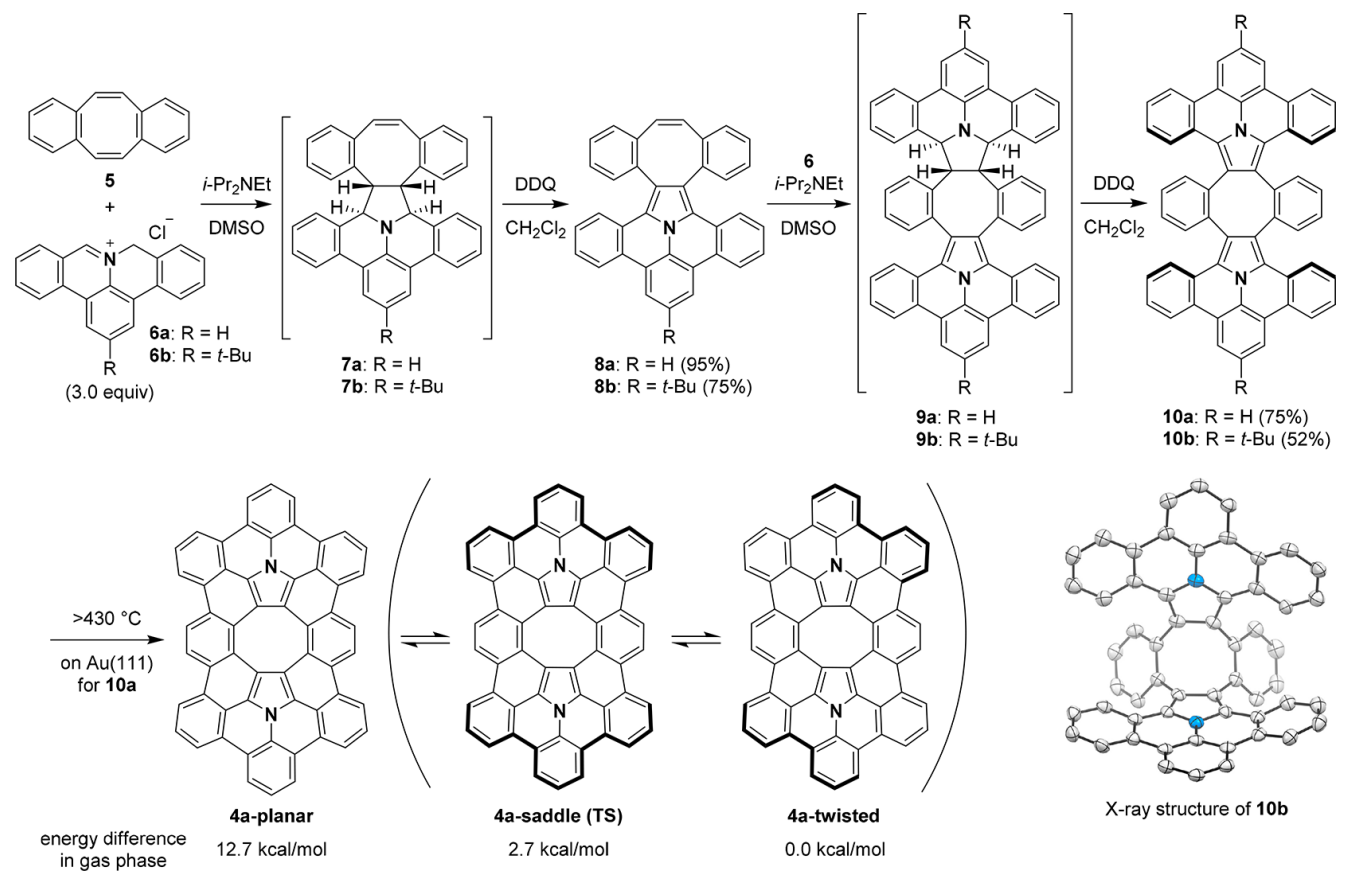

Scheme 2. Energy Diagram of 1,3-Dipolar Cycloaddition Reactions of Dibenzo[a,e $]$ cyclooctatetraene 5 and the Azomethine Ylide Prepared from 6 a

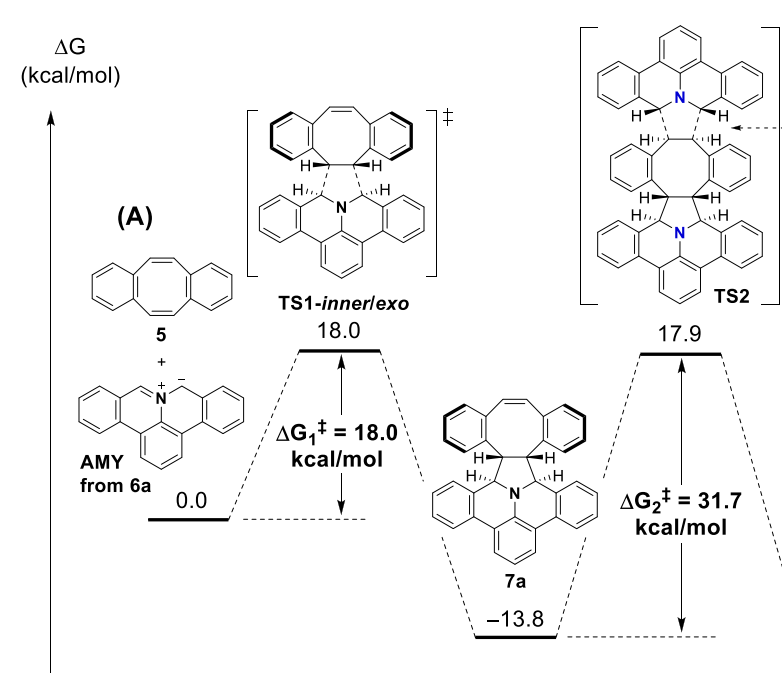

$p$-benzoquinone (DDQ) to obtain monocycloadducts 8 in good yields. It is worth noting that the formation of dicycloadducts was not detected, although excess amounts of the azomethine ylides were reacted with $\mathbf{5}$ possessing two reactive carbon-carbon double bonds. Thus, it was necessary to repeat the same cycloaddition reaction to convert pyrroles 8 into diadducts $\mathbf{1 0}$ through pyrrolidine intermediates $\mathbf{9}$. All of the products were characterized by NMR spectroscopy and mass spectrometry (MS). In addition, single crystals suitable for X-ray diffraction analysis were obtained for compounds $\mathbf{7 b}$ $\mathbf{8 b}, \mathbf{9 b}$, and $\mathbf{1 0 b}{ }^{24}$ The structure of $\mathbf{1 0 b}$ shown in Scheme 1 revealed $\mathbf{1 0}$ to have a tub-shaped structure.

In order to gain insight into the monoselectivity of the first 1,3-dipolar cycloaddition reaction, density functional theory
(DFT) calculations at the B3LYP/6-31G(d) level were conducted (Scheme 2). In the first step, to form $\mathbf{7 a}$, four possible stereoisomers derived from inner/outer and exo/endo structures need to be considered (Figure S24). Among them, the inner/exo addition gave the most stable transition state TS1 and the product 7a (Scheme 2A). The activation energy of the first transition state $\operatorname{TS} 1\left(\Delta G^{\ddagger}\right)$ was calculated to be $18.0 \mathrm{kcal} / \mathrm{mol}$, while those of the other pathways exceeded 20 $\mathrm{kcal} / \mathrm{mol}$. This is consistent with our experimental results that only the inner/exo isomer was isolated. The activation energies of the second addition of the azomethine ylide to $7 \mathbf{a}\left(\Delta \mathrm{G}^{\neq}{ }_{2}\right)$ were also calculated (Scheme $2 \mathrm{~A})$. In this case, a reaction in an outer/exo manner gave the lowest energy of $31.7 \mathrm{kcal} / \mathrm{mol}$. In contrast, the cycloaddition reaction to $\mathbf{8 a}$ gave a relatively 
lower activation barrier $\left(\Delta \mathrm{G}_{3}^{\neq}\right)$of $20.0 \mathrm{kcal} / \mathrm{mol}$ (Scheme $2 \mathrm{~B}$ ). The fact that $\Delta G^{\ddagger}{ }_{2}$ is higher than $\Delta G^{\ddagger}{ }_{3}$ could be the reason why the second addition did not occur even in the presence of an excess amount of azomethine ylide.

We devoted considerable efforts to convert 10a to $4 \mathbf{a}$ by a synthesis in solution, but all of those attempts failed. Therefore, we turned our focus to on-surface synthesis. ${ }^{16}$ 10a was deposited on $\mathrm{Au}(111)$ under ultrahigh vacuum at room temperature and then observed by scanning tunneling microscopy (STM) at $4.3 \mathrm{~K}$ (Figure 2A). The molecules were
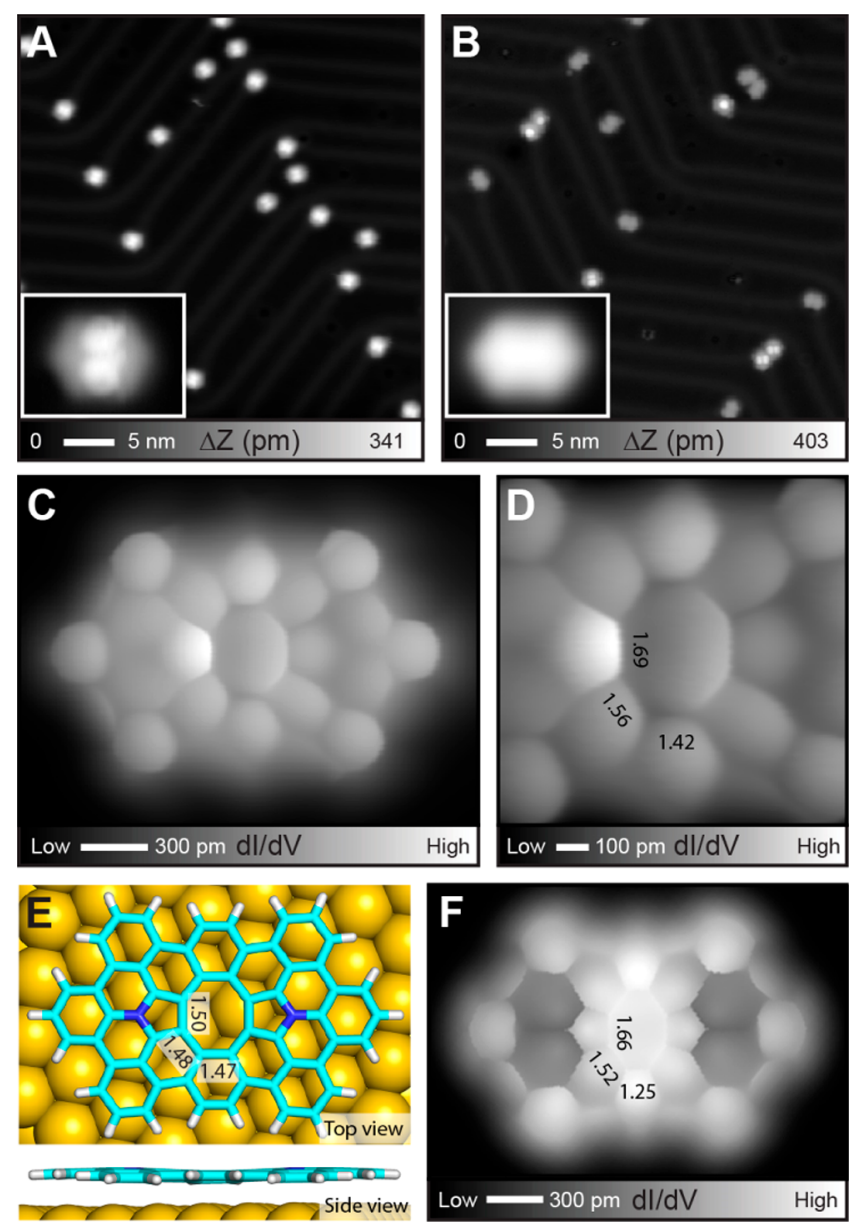

Figure 2. On-surface reaction of 10a on $\mathrm{Au}(111)$ to form 4a. (A) Overview STM topography of as-deposited 10a $\left(V_{\text {bias }}=500 \mathrm{mV}, I=1\right.$ $\mathrm{pA})$. The inset shows a close-up view of a single molecule $\left(V_{\text {bias }}=200\right.$ $\mathrm{mV}, I=5 \mathrm{pA}$ ). (B) Overview STM topography after annealing at 430 ${ }^{\circ} \mathrm{C}$. The inset shows a close-up view $\left(V_{\text {bias }}=200 \mathrm{mV}, I=2 \mathrm{pA}\right)$. (C, D) High-resolution CO-STM images of a single $4 \mathbf{a}\left(V_{\text {bias }}=3 \mathrm{mV}\right)$. The measured apparent bond lengths (in $\AA$ ) of the central octagon are shown in (D). (E) Molecular structure of 4a based on DFT calculations on $\mathrm{Au}(111)$. The bond lengths (in $\AA$ ) of the central octagon are shown. (F) Simulated constant-height CO-STM image of DFT-calculated $\mathbf{4 a}$ on the $\mathrm{Au}(111)$ surface at $0 \mathrm{~V}$.

located at the elbow sites of the herringbone structure. In addition to the natural tub conformation of the octagon, steric effect lifted the phenyl groups attached to the central octagon up from the substrate (Figure 2A inset and Figure S19). Subsequently, the sample was annealed at ca. $700 \mathrm{~K}$ to induce cyclodehydrogenation. Figure $2 \mathrm{~B}$ shows the overview STM topography. It was found that some of the molecules became planar (Figure 2B inset), while some remained unchanged. Since the numbers of molecules on the surface observed before and after the annealing were almost the same, the molecular mass and the adsorption energy are high enough to prevent thermal desorption during annealing. To resolve the inner structures of the molecules, the metal tip was terminated with a CO molecule. ${ }^{25}$ Figure 2C,D shows the high-resolution CO-STM images in constant-height mode. Apparently, the dehydrogenative cyclization of 10a proceeded to form 4 a (for the side products, see Figures S22 and S23). The pronounced sharp edges in the image confirm that the molecule on the $\mathrm{Au}(111)$ surface is planar. The small bilaterally asymmetric contrasts in the image may relate to asymmetric tilting of the CO tip (Figure S36). ${ }^{26}$ The high planarity of the central octagon allowed us to investigate the bond order variations via the apparent lengths in the CO-STM images (Figure 2C). ${ }^{27}$ To reduce the effect of the asymmetric tip, the mean values of the apparent lengths over equivalent sites of the central octagon in $\mathbf{4 a}$ were taken. We found a significant variation in the apparent lengths as 1.42, 1.56, and $1.69 \AA$ (Figure 2D), indicating a certain variation in the bond orders as well. Our DFT calculations on $\mathrm{Au}(111)$ also showed a variation in the bond lengths (Figure 2E), although the differences were rather small. In order to investigate the validity of the comparison, we calculated the PP-STM image of the DFT-calculated structure. Indeed, the simulated PP-STM image (Figures 2F and S36) also shows a significant deviation in the apparent bond lengths, and the order of the apparent bond lengths is consistent with that in the experiment. Therefore, it is unambiguously concluded that the planarized octagon has a certain deviation of the bond order. In addition, the octagon looks highly distorted from a regular octagon, presumably because of the large sum of the wedge angles of the surrounding six hexagons and two pentagons. These results indicate that the central octagon is highly strained by the formation of the 4 a structure as well as further planarization on $\mathrm{Au}(111)$. This steric frustration is also supported by DFT calculations on $\mathbf{4 a}$ in the gas phase, which indicated a twisted-shaped structure as the most stable state compared with the saddle-shaped $(2.7 \mathrm{kcal} /$ mol) and planar $(12.7 \mathrm{kcal} / \mathrm{mol})$ conformations (Scheme 1 and Figure S26).

Next we discuss the aromaticity because there has been continued interest in the aromaticity of cyclooctatetraene

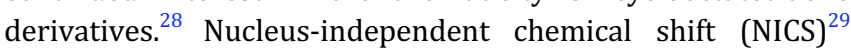
calculations on 10a and $4 \mathrm{a}$ were performed in the gas phase. In 10a, the pyrrole rings and the peripheral benzene rings show large negative $\operatorname{NICS}(0)$ values (all in ppm) ranging from -7.7 to -16.0 , while the central octagon shows a value of 3.6 , which means that it is slightly antiaromatic (Figure S28). After conversion to $\mathbf{4 a}$, the NICS $(0)$ value increased to 7.4 , which indicates an enhancement of the antiaromaticity upon planarization (Figure 3A). This $\operatorname{NICS}(0)$ value of 7.4 is comparable to those of other hetero[8]circulenes $\mathbf{2}$ including oxygen and nitrogen (6.5-8.6) and 3 including sulfur and selenium (5.6-5.7). ${ }^{1,5 a}$ In order to get further insight, the anisotropy of the induced current density $(\mathrm{ACID})^{30}$ of $\mathbf{4 a}$ was calculated in the gas phase (Figures 3B, S31, and S32). The plot clearly shows a counterclockwise $8 \pi$ ring current flowing along the central octagon ring as well as a clockwise $40 \pi$ ring current flowing along the outer fused rings, including the two pyrrole rings. The observation of a diatropic $40 \pi$ ring current is consistent with those of other hetero[8]circulenes, which typically show internal paratropic $8 \pi$ ring currents surrounded by outer diatropic $24 \pi$ ring currents. ${ }^{31}$ Although the shapes of 
A
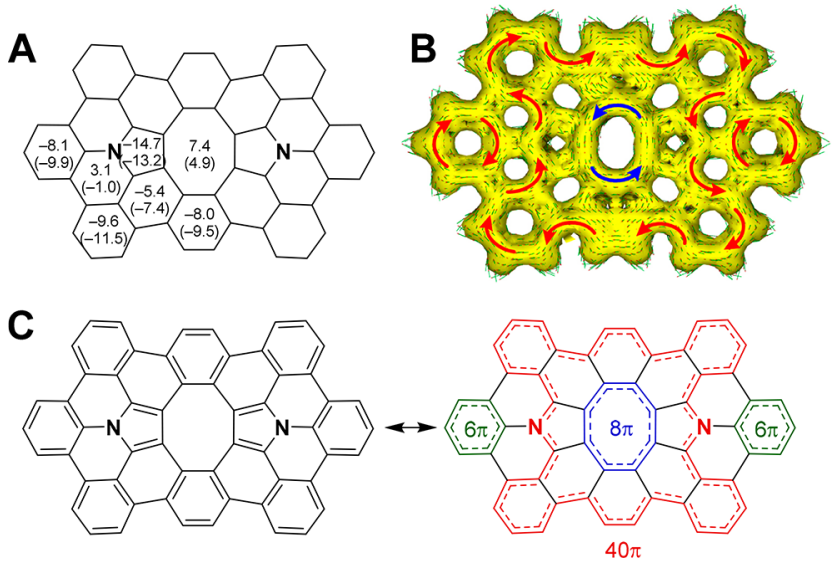

Figure 3. (A) NICS(0) values for planar 4a calculated in the gas phase. NICS(1) values are shown in parentheses. (B) ACID plot for 4a calculated in the gas phase. (C) Bond alternation patterns of $\mathbf{4 a}$

the ring currents are not significantly affected by the change the conformation of $\mathbf{4 a}$ (Figures S31 and S32), the efficiency of the diatropic $40 \pi$ conjugation is maximized in the planar geometry, as the simulated ${ }^{1} \mathrm{H}$ NMR signals in Figure S29 show larger shifts toward lower fields. Combined with the NICS calculations and bond lengths (Figure S27), these results suggested the presence of two major contributing electronic structures, one having two $6 \pi$ pyrrole rings and eight benzene rings (left in Figure 3C) and the other having inner $8 \pi$, outer $40 \pi$, and two $6 \pi$ conjugations (right in Figure 3C). should be noted that metal surfaces were not considered in above NICS and ACID calculations, but we consider the discussion to be valid for $\mathbf{4 a}$ on the metal surface because of the similarity of the frontier orbitals in the gas phase and on the metal surface (as shown by comparison of Figures $4 \mathrm{G}$ andS35) and the consistency with the experimental $\mathrm{dI} / \mathrm{dV}$ curves Figures 4D). In addition, the charge transfer plot (Figure S34) strongly suggested that the charge transfer between 4a and the metal surface is marginal.

Finally, we investigated the electronic structure of $\mathbf{4 a}$ on $\mathrm{Au}(111)$ with $\mathrm{dI} / \mathrm{dV}$ mapping at various energies (Figure $4 \mathrm{~A}-$ C) and scanning tunneling spectroscopy at specific positions (Figure 4D). The lowest unoccupied molecular orbital LUMO), at $2.2 \mathrm{~V}$, was clearly observed at positions 1 and 2 in Figure 4D. This is consistent with the on-gold calculated simulation in Figure $4 \mathrm{~F}$ and the vacuum-calculated LUMO in Figure $4 \mathrm{G}$, in which the LUMO is mainly localized at the peripheral benzene rings. In contrast, the highest occupied molecular orbital (HOMO), at $-0.9 \mathrm{~V}$, and HOMO-1, at $-1.2 \mathrm{~V}$, were clearly observed at positions 3 and 4 , which is also supported by the simulated HOMOs (Figure 4E,G). Thus, the HOMO-LUMO gap was determined to be $3.1 \mathrm{eV}$, which is consistent with the value of $3.08 \mathrm{eV}$ calculated in vacuum (Figure 4G). The on-gold DFT calculations also show peaks for HOMOs and LUMOs near the Fermi Level, and their electron densities (Figure S35) are in agreement with gasphase-calculated wave functions.

In summary, a combined in-solution and on-surface approach resulted in the successful synthesis of $\pi$-extended diaza[8]circulene 4. High-resolution CO-STM elucidated that the molecule adopts a planar conformation on $\mathrm{Au}(111)$ and has a unique electronic structure due to the introduction of multiple nitrogen atoms into the PAH framework. DFT calculations fully supported the experimental results. This work
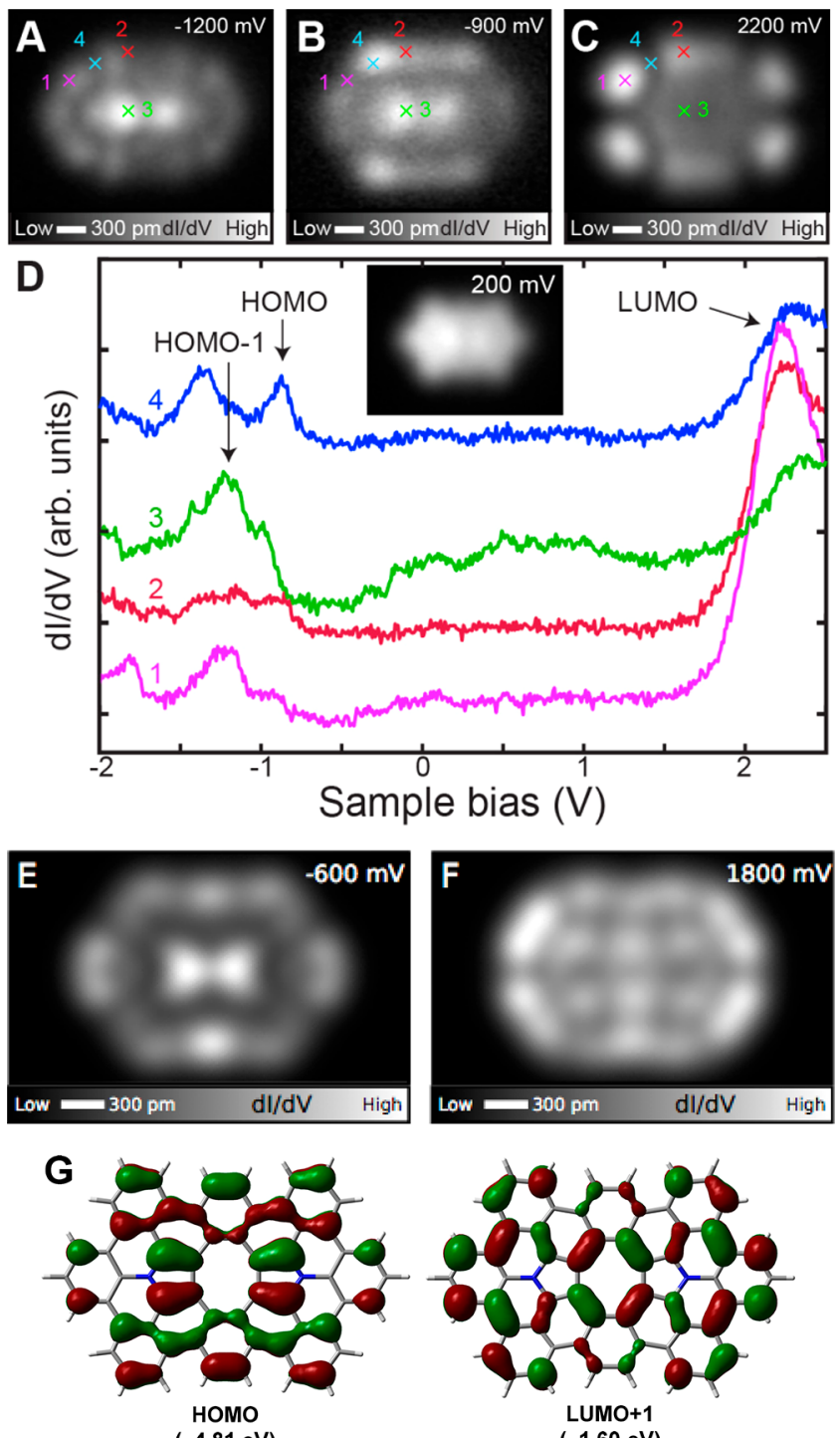

$(-4.81 \mathrm{eV})$
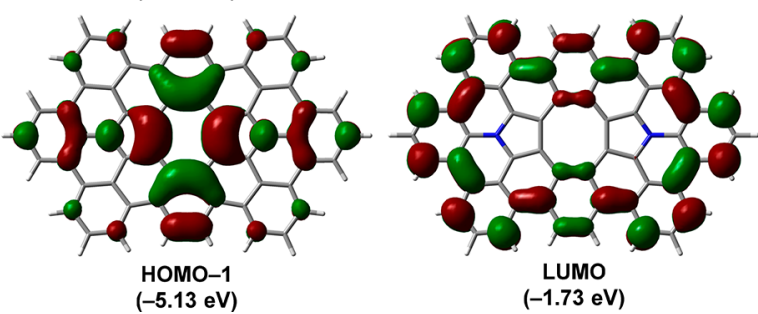

Figure 4. (A-C) Constant-height differential conductance maps above $4 \mathrm{a}$ at various energies measured with the $\mathrm{CO}$ tip in the far distance. (D) $\mathrm{d} I / \mathrm{d} V$ curves measured at the sites indicated in $(\mathrm{A}-\mathrm{C})$. (E, F) Simulated STM images of the on-surface molecule at energies close to those of (E) the HOMO and (F) the LUMO. (G) Frontier molecular orbitals of $\mathbf{4 a}$ calculated in vacuum.

demonstrates the power of a combined in-solution and onsurface approach for the synthesis of unprecedented nitrogencontaining PAH molecules that could not otherwise be synthesized.

\section{ASSOCIATED CONTENT}

\section{Supporting Information}

The Supporting Information is available free of charge at https://pubs.acs.org/doi/10.1021/jacs.0c02534. 
Experimental procedures, compound characterization, spectra, details of DFT calculations, CO-STM images, and $\mathrm{dI} / \mathrm{dV}$ simulations (PDF)

X-ray crystallographic data for $\mathbf{7 b}$ (CIF)

$\mathrm{X}$-ray crystallographic data for $\mathbf{8 b}$ (CIF)

X-ray crystallographic data for $\mathbf{9 b}$ (CIF)

X-ray crystallographic data for $\mathbf{1 0 b}$ (CIF)

\section{AUTHOR INFORMATION}

\section{Corresponding Authors}

Shigeki Kawai - International Center for Materials Nanoarchitectonics, National Institute for Materials Science, Tsukuba, Ibaraki 305-0044, Japan; orcid.org/0000-0003-21280120; Email: Kawai.Shigeki@nims.go.jp

Adam S. Foster - Department of Applied Physics, Aalto University, Aalto 00076, Finland; WPI Nano Life Science Institute (WPI-NanoLSI), Kanazawa University, Kanazawa 920-1192, Japan; orcid.org/0000-0001-5371-5905; Email: adam.foster@aalto.fi

Shingo Ito - Division of Chemistry and Biological Chemistry, School of Physical and Mathematical Sciences, Nanyang Technological University, Singapore 637371 Singapore; orcid.org/0000-0003-1776-4608; Email: sgito@ntu.edu.sg

\section{Authors}

Kimihiro Nakamura - Division of Chemistry and Biological Chemistry, School of Physical and Mathematical Sciences, Nanyang Technological University, Singapore 637371 Singapore Qiang-Qiang Li - Division of Chemistry and Biological Chemistry, School of Physical and Mathematical Sciences, Nanyang Technological University, Singapore 637371 Singapore; orcid.org/0000-0002-8268-7488

Ondřej Krejčí -Department of Applied Physics, Aalto University, Aalto 00076, Finland; orcid.org/0000-0002-4948-4312

Kewei Sun - International Center for Materials

Nanoarchitectonics, National Institute for Materials Science, Tsukuba, Ibaraki 305-0044, Japan

Complete contact information is available at: https://pubs.acs.org/10.1021/jacs.0c02534

\section{Author Contributions}

${ }^{\perp}$ K.N. and Q.-Q.L. contributed equally.

\section{Notes}

The authors declare no competing financial interest.

\section{ACKNOWLEDGMENTS}

This work was supported in part by Nanyang Technological University (S.I.), the Singapore Ministry of Education via Academic Research Fund Tier 1:2018-T1-002-021 (S.I.), and Japan Society for the Promotion of Science (JSPS) through KAKENHI Grant 19H00856 (S.K.). K.N. thanks NTU for the SPMS International Internship Program. O.K. was supported by the European Union's Horizon 2020 Research and Innovation Programme under Marie Skłodowska-Curie Grant Agreement 845060. A.S.F. was supported by the World Premier International Research Center Initiative (WPI), MEXT, Japan. Computing resources from the Aalto Science- IT Project and CSC, Helsinki, are gratefully acknowledged. S.K. sincerely thanks Prof. Ernst Meyer, Dr. Urs Gysin, Dr. Sascha Martin, and Dr. Yves Pellmont for their support to build the low-temperature ultrahigh-vacuum atomic force microscopy/scanning tunneling microscopy system. S.I. sincerely thanks Prof. Rei Kinjo and Ms. Kei Ota (NTU) for ACID analysis and Prof. Naoki Aratani for the fruitful discussion during the preparation of this Communication.

\section{REFERENCES}

(1) Hensel, T.; Andersen, N. N.; Plesner, M.; Pittelkow, M. Synthesis of heterocyclic [8]circulenes and related structures. Synlett 2016, 27, 498-525.

(2) (a) Mackay, A. L.; Terrones, H. Diamond form graphite. Nature 1991, 352, 762. (b) Pun, H. S.; Miao, Q. Toward negatively curved carbons. Acc. Chem. Res. 2018, 51, 1630-1642.

(3) (a) Feng, C.-N.; Kuo, M.-Y.; Wu, Y.-T. Synthesis, structural analysis, and properties of [8]circulenes. Angew. Chem., Int. Ed. 2013 52, 7791-7794. (b) Feng, C.-N.; Hsu, W.-C.; Li, J.-Y.; Kuo, M.-Y.; $\mathrm{Wu}$, Y.-T. Per-substituted [8]circulene and its non-planar fragments: Synthesis, structural analysis, and properties. Chem. - Eur. J. 2016, 22, 9198-9208.

(4) (a) Sakamoto, Y.; Suzuki, T. Tetrabenzo[8]circulene: Aromatic saddles from negatively curved graphene. J. Am. Chem. Soc. 2013, 135 , 14074-14077. (b) Miller, R. W.; Duncan, A. K.; Schneebeli, S. T.; Gray, D. L.; Whalley, A. C. Synthesis and structural data of tetrabenzo [8]circulene. Chem. - Eur. J. 2014, 20, 3705-3711. (c) Pun, S. H.; Wang, Y.; Chu, M.; Chan, C. K.; Li, Y.; Liu, Z.; Miao, Q. Synthesis, structures, and properties of heptabenzo[7]circulene and octabenzo[8] circulene. J. Am. Chem. Soc. 2019, 141, 9680-9686.

(5) For reviews, see: (a) Baryshnikov, G. V.; Minaev, B. F.; Minaeva, V. A. Electronic structure, aromaticity and spectra of hetero[8]circulenes. Russ. Chem. Rev. 2015, 84, 455-484. (b) Karaush, N. N.; Baryshnikov, G. V.; Minaeva, V. A.; Ågren, H.; Minaev, B. F. Recent progress in quantum chemistry of hetero[8]circulenes. Mol. Phys. $2017,115,2218-2230$ and references cited therein.

(6) (a) Chernichenko, K. Y.; Sumerin, V. V.; Shpanchenko, R. V.; Balenkova, E. S.; Nenajdenko, V. G. Sulflower": A new form of carbon sulfide. Angew. Chem., Int. Ed. 2006, 45, 7367-7370. (b) Dadvand, A.; Cicoira, F.; Chernichenko, K. Y.; Balenkova, E. S.; Osuna, R. M.; Rosei, F.; Nenajdenko, V. G.; Perepichka, D. F. Heterocirculenes as a new class of organic semiconductors. Chem. Commun. 2008, 53545356.

(7) (a) Ohmae, T.; Nishinaga, T.; Wu, M.; Iyoda, M. Cyclic tetrathiophenes planarized by silicon and sulfur bridges bearing antiaromatic cyclooctatetraene core: syntheses, structures, and properties. J. Am. Chem. Soc. 2010, 132, 1066-1074. (b) Nishinaga, T.; Ohmae, T.; Aita, K.; Takase, M.; Iyoda, M.; Arai, T.; Kunugi, Y. Antiaromatic planar cyclooctatetraene: a strategy for developing ambipolar semiconductors for field effect transistors. Chem. Commun. 2013, 49, 5354-5356.

(8) (a) Nielsen, C. B.; Brock-Nannestad, T.; Reenberg, T. K.; Hammershøj, P.; Christensen, J. B.; Stouwdam, J. W.; Pittelkow, M. Organic light-emitting diodes from symmetrical and unsymmetrical $\pi$ extended tetraoxa[8]circulenes. Chem. - Eur. J. 2010, 16, 1303013034. (b) Baryshnikov, R. R.; Valiev, N. N.; Karaush, V. A.; Minaeva, A. N.; Sinelnikov, G. V.; Pedersen, S. K.; Pittelkow, M.; Minaev, B. F.; Ågren, H. Benzoannelated aza-, oxa- and azaoxa[8]circulenes as promising blue organic emitters. Phys. Chem. Chem. Phys. 2016, 18, 28040-28051.

(9) (a) Eskildsen, J.; Reenberg, T.; Christensen, J. B. Substituted tetraoxa[8]circulenes - New members of the liquid crystal family. Eur. J. Org. Chem. 2000, 2000, 1637-1640. (b) Mejlsøe, S. L.; Christensen, J. B. Synthesis and characterization of geminally dialkylsubstituted tetraindanotetraoxa[8]circulenes. J. Heterocyc. Chem. 2014, 51, 1051-1057.

(10) For compounds 2 bearing four hexagons and four pentagons, see: (a) Berg, J.-E.; Erdtman, H.; Högberg, H.-E.; Karlsson, B.; Pilotti, A.-M.; Söderholm, A.-C. Quinone oligomerization, an X-ray study. Tetrahedron Lett. 1977, 18, 1831-1834. (b) Nielsen, C.; BrockNannestad, T.; Hammershoj, P.; Reenberg, T.; Schau-Magnussen, M.; 
Trpcevski, D.; Hensel, T.; Salcedo, R.; Baryshnikov, G.; Minaev, B.; Pittelkow, M. Azatrioxa[8]circulenes: Planar anti-aromatic cyclooctatetraenes. Chem. - Eur. J. 2013, 19, 3898-3904. (c) Hensel, T Trpcevski, D.; Lind, C.; Grosjean, R.; Hammershøj, C. B.; Nielsen, C Brock-Nannestad, T.; Nielsen, B.; Schau-Magnussen, M.; Minaev, B Baryshnikov, G.; Pittelkow, M. Diazadioxa[8]circulenes: antiaromatic cyclooctatetraenes. Chem. - Eur. J. 2013, 19, 17097 17102. (d) Nakamura, Y.; Aratani, N.; Shinokubo, H.; Takagi, A Kawai, T.; Matsumoto, T.; Yoon, Z. S.; Kim, D. Y.; Ahn, T. K.; Kim, D.; Muranaka, A.; Kobayashi, N.; Osuka, A. A directly tetrameric porphyrin sheet and its anomalous electronic properties that arise from the planar cyclooctatetraene core. J. Am. Chem. Soc. 2006, 128, 4119-4127. (e) Chen, F.; Hong, Y. S.; Shimizu, S.; Kim, D.; Tanaka, T.; Osuka, A. Synthesis of a tetrabenzotetraaza[8]circulene by a "fold-in" oxidative fusion reaction. Angew. Chem., Int Ed. 2015, 54, 10639-10642. (f) Xiong, X.; Deng, C.-L.; Minaev, B F.; Baryshnikov, G. V.; Peng, X.-S.; Wong, H. N. Tetrathio and tetraseleno[8]circulenes: synthesis, structures, and properties. Chem. sian J. 2015, 10, 969-975. (g) Xiong,X.; Deng, C.-L. ;Li, Z.; Peng X.-S.; Wong, H. N. C. Quasi-planar diazadithio and diazodiseleno[8]circulenes: synthesis, structures and properties. Org. Chem. Front 2017, 4, 682-687. (h) Nagata, Y.; Kato, S.; Miyake, Y.; Shinokubo H. Synthesis of tetraaza[8]circulenes from tetrathia[8] through an $\mathrm{S}_{\mathrm{N}}$ Ar-based process. Org. Lett. 2017, 19, 2718-2721 (i) Kato, S.; Akahori, S.; Serizawa, Y.; Lin, X.; Yamauchi, M.; Yagai, S Sakurai, T.; Matsuda, W.; Seki, S.; Shinokubo, H.; Miyake, Y. Systematic synthesis of tetrathia[8]circulenes: The influence of peripheral substituents on the structures and properties in and solid states. J. Org. Chem. 2020, 85, 62-69.

(11) (a) Fujimoto, T.; Suizu, R.; Yoshikawa, H.; Awaga, K. Molecular, Crystal, and Thin-Film Structures of Octathio[8]circulene: Release of antiaromatic molecular distortion and lamellar structure of self-assembling thin films. Chem. - Eur. J. 2008, 14, 6053-6056. (b) Fujimoto, T.; Matsushita, M. M.; Yoshikawa, H.; Awaga, K. Electrochemical and electrochromic properties of octathio[8]circulene thin films in ionic liquids. J. Am. Chem. Soc. 2008, 130, 15790-15791. (c) Fujimoto, T.; Matsushita, M. M.; Awaga, K. Dualgate field-effect transistors of octathio[8]circulene thin-films with ionic liquid and $\mathrm{SiO}_{2}$ gate dielectrics. Appl. Phys. Lett. 2010, 97, 123303. (d) Fujimoto, T.; Matsushita, M. M.; Awaga, K. Ionic-liquid component dependence of carrier injection and mobility for electricdouble-layer organic thin-film transistors. J. Phys. Chem. C 2012, 116, 5240-5245. (e) Kato, S.; Serizawa, Y.; Sakamaki, D.; Seki, S.; Miyake, Y.; Shinokubo, H. Diversity - oriented synthesis of tetrathia [8] circulenes by sequential $\mathrm{C}-\mathrm{H}$ borylation and annulation. Chem. Commun. 2015, 51, 16944-16947. (f) Serizawa, Y.; Akahori, S.; Kato, S.; Sakai, H.; Hasobe, T.; Miyake, Y.; Shinokubo, H. Synthesis of Tetrasilatetrathia[8]circulenes by a fourfold intramolecular dehydrogenative silylation of C-H bonds. Chem. - Eur. J. 2017, 23, 69486952. (g) Akahori, S.; Sakai, H.; Hasobe, T.; Shinokubo, H.; Miyake, Y. Synthesis and photodynamics of tetragermatetrathia[8]circulene. Org. Lett. 2018, 20, 304-307.

(12) Ito, S.; Tokimaru, Y.; Nozaki, K. Isoquinolino[4,3,2-de]phenanthridine: Synthesis and its use in 1,3-dipolar cycloadditions to form nitrogen-containing polyaromatic hydrocarbons. Chem. Commun. 2015, 51, 221-224.

(13) Berger, R.; Giannakopoulos, A.; Ravat, P.; Wagner, M.; Beljonne, D.; Feng, X.; Müllen, K. Synthesis of nitrogen-doped zigzagedge peripheries: dibenzo-9a-azaphenalene as repeating unit. Angew. Chem., Int. Ed. 2014, 53, 10520-10524. (b) Berger, R.; Wagner, M.; Feng, X.; Müllen, K. Polycyclic aromatic azomethine ylides: a unique entry to extended polycyclic heteroaromatics. Chem. Sci. 2015, 6, 436-441. (c) Richter, M.; Schellhammer, K. S.; Machata, P.; Cuniberti, G.; Popov, A.; Ortmann, F.; Berger, R.; Müllen, K.; Feng, X. Polycyclic heteroaromatic hydrocarbons containing a benzoisoindole core. Org. Chem. Front. 2017, 4, 847-852. (d) Richter, M.; Hahn, S.; Dmitrieva, E.; Rominger, F.; Popov, A.; Bunz, U. H. F.; Feng, X.; Berger, R. Helical ullazine-quinoxaline-based polycyclic aromatic hydrocarbons. Chem. - Eur. J. 2019, 25, 1345-1352.
(14) (a) Ito, S.; Tokimaru, Y.; Nozaki, K. Benzene-fused azacorannulene bearing an internal nitrogen atom. Angew. Chem., Int. Ed. 2015, 54, 7256-7260. (b) Tokimaru, Y.; Ito, S.; Nozaki, K. Synthesis of pyrrole-fused corannulenes: 1,3-Dipolar cycloaddition of azomethine ylides to corannulene. Angew. Chem., Int. Ed. 2017, 56, 15560-15564. (c) Tokimaru, Y.; Ito, S.; Nozaki, K. A Hybrid of corannulene and azacorannulene: Synthesis of a highly curved nitrogen-containing buckybowl. Angew. Chem., Int. Ed. 2018, 57, 9818-9822. (d) Nagano, T.; Nakamura, K.; Tokimaru, Y.; Ito, S.; Miyajima, D.; Aida, T.; Nozaki, K. Functionalization of azapentabenzocorannulenes by fivefold $\mathrm{C}-\mathrm{H}$ borylation and cross-coupling arylation: Application to columnar liquid-crystalline materials. Chem. Eur. J. 2018, 24, 14075-14078. (e) Zhou, Z.; Wei, Z.; Tokimaru, Y.; Ito, S.; Nozaki, K.; Petrukhina, M. A. Stepwise reduction of azapentabenzocorannulene. Angew. Chem., Int. Ed. 2019, 58, 12107-12111.

(15) Wang, X.-Y.; Richter, M.; He, Y.; Björk, J.; Riss, A.; Rajesh, R.; Garnica, M.; Hennersdorf, F.; Weigand, J. J.; Narita, A.; Berger, R.; Feng, X.; Auwar̈ter, W.; Barth, J. V.; Palma, C.-A.; Müllen, K. Nat. Commun. 2017, 8, 1948.

(16) (a) Sun, Q.; Zhang, R.; Qiu, J.; Liu, R.; Xu, W. On-surface synthesis of carbon nanostructures. Adv. Mater. 2018, 30, 1705630. (b) Singh, V.; Joung, D.; Zhai, L.; Das, S.; Khondaker, S. I.; Seal, S. Graphene based materials: Past, present and future. Prog. Mater. Sci. 2011, 56, 1178-1271. (c) Jariwala, D.; Sangwan, V. K.; Lauhon, L. J.; Marks, T. J.; Hersam, M. C. Carbon nanomaterials for electronics, optoelectronics, photovoltaics, and sensing. Chem. Soc. Rev. 2013, 42, 2824-2860. (d) Allen, M. J.; Tung, V. C.; Kaner, R. B. Honeycomb carbon: A review of graphene. Chem. Rev. 2010, 110, 132-145.

(17) For representative examples, see: (a) Cai, J.; Ruffieux, P.; Jaafar, R.; Bieri, M.; Braun, T.; Blankenburg, S.; Muoth, M.; Seitsonen, A. P.; Saleh, M.; Feng, X.; Mullen, K.; Fasel, R. Atomically precise bottomup fabrication of graphene nanoribbons. Nature 2010, 466, 470-473. (b) Kawai, S.; Saito, S.; Osumi, S.; Yamaguchi, S.; Foster, A. S.; Spijker, P.; Meyer, E. Atomically controlled substitutional borondoping of graphene nanoribbons. Nat. Commun. 2015, 6, 8098. (c) Kawai, S.; Nakatsuka, S.; Hatakeyama, T.; Pawlak, R.; Meier, T.; Tracey, J.; Meyer, E.; Foster, A. S. Multiple heteroatom substitution to graphene nanoribbon. Sci. Adv. 2018, 4, eaar7181.

(18) Sanchez-Valencia, J. R.; Dienel, T.; Groning, O.; Shorubalko, I.; Mueller, A.; Jansen, M.; Amsharov, K.; Ruffieux, P.; Fasel, R. Controlled synthesis of single-chirality carbon nanotubes. Nature $2014,512,61-64$.

(19) Otero, G.; Biddau, G.; Sańchez - Sańchez, C.; Caillard, R.; Loṕez, M. F.; Rogero, C.; Palomares, F. J.; Cabello, N.; Basanta, M. A.; Ortega, J.; Meńdez, J.; Echavarren, A. M.; Peŕez, R.; Goméez-Lor, B.; Martín-Gago, J. A. Fullerenes from aromatic precursors by surfacecatalysed cyclodehydrogenation. Nature 2008, 454, 865-868.

(20) Kruger, J.; Garcia, F.; Eisenhut, F.; Skidin, D.; Alonso, J. M.; Guitian, E.; Perez, D.; Cuniberti, G.; Moresco, F.; Pena, D. Decacene: on-surface generation. Angew. Chem., Int. Ed. 2017, 56, 11945-11948.

(21) Rogers, C.; Chen, C.; Pedramrazi, Z.; Omrani, A. A.; Tsai, H. Z.; Jung, H. S.; Lin, S.; Crommie, M. F.; Fischer, F. R. Closing the Nanographene Gap: Surface-assisted synthesis of peripentacene from 6,6'-bipentacene precursors. Angew. Chem., Int. Ed. 2015, 54, 1514315146.

(22) (a) Sutter, P. W.; Flege, J. I.; Sutter, E. A. Epitaxial graphene on ruthenium. Nat. Mater. 2008, 7, 406-411. (b) Treier, M.; Pignedoli, C. A.; Laino, T.; Rieger, R.; Mullen, K.; Passerone, D.; Fasel, R. Surface-assisted cyclodehydrogenation provides a synthetic route towards easily processable and chemically tailored nanographenes. Nat. Chem. 2011, 3, 61-67. (c) Hieulle, J.; Carbonell-Sanroma, E.; Vilas-Varela, M.; Garcia-Lekue, A.; Guitian, E.; Pena, D.; Pascual, J. I. On-surface route for producing planar nanographenes with azulene moieties. Nano Lett. 2018, 18, 418-423.

(23) Mishra, S.; Krzeszewski, M.; Pignedoli, C. A.; Ruffieux, P.; Fasel, R.; Gryko, D. T. On-surface synthesis of a nitrogen-embedded buckybowl with inverse Stone-Thrower-Wales topology. Nat. Commun. 2018, 9, 1714. 
(25) (a) Gross, L.; Mohn, F.; Moll, N.; Liljeroth, P.; Meyer, G. The chemical structure of a molecule resolved by atomic force microscopy. Science 2009, 325, 1110-1114. (b) Kichin, G.; Weiss, C.; Wagner, C.; Tautz, F. S.; Temirov, R. Single molecule and single atom sensors for atomic resolution imaging of chemically complex surfaces. J. Am. Chem. Soc. 2011, 133 (42), 16847-16851.

(26) (a) Hapala, P.; Kichin, G.; Wagner, C.; Tautz, F. S.; Temirov, R.; Jelínek, P. Mechanism of high-resolution STM/AFM imaging with functionalized tips. Phys. Rev. B: Condens. Matter Mater. Phys. 2014, 90, No. 085421. (b) Hapala, P.; Temirov, R.; Tautz, F. S.; Jelínek, P. Origin of high-resolution IETS-STM images of organic molecules with functionalized tips. Phys. Rev. Lett. 2014, 113, 226101. (c)Krejcì, 0.; Hapala, P.; Ondraćěk, M.;jelínek, P. Principles and simulations of high-resolution STM imaging with a flexible tip apex. Phys. Rev. B: Condens. Matter Mater. Phys. 2017, 95, No. 045407.

(27) (a) Gross, L.; Mohn, F.; Moll, N.; Schuller, B.; Criado, A.; Guitiań, E.; Peña, D.; Gourdon, A.; Meyer, G. Science 2012 , 337, 1326-1329. (b) Kawai, S.; Takahashi, K.; Ito, S.; Pawlak, R.; Meier, T.; Spijker, P.; Canova, F. F.; Tracey, J.; Nozaki, K.; Foster, A. S.; Meyer, E. Competing annulene and radialene structures in a single anti-aromatic molecule studied by high-resolution atomic force microscopy. ACS Nano 2017, 11, 8122-8130. (28) Nishinaga, T.; Ohmae, T.; Iyoda, M. Recent studies on the aromaticity and antiaromaticity of planar cyclooctatetraene. Symmetry 2010, 2, 76-97.

(29) Schleyer, P. v. R.; Maerker, C.; Dransfeld, A.; Jiao, H. J.; van Eikema Hommes, N. J. R. V. Nucleus-independent chemical shifts (NICS) as an aromaticity criterion. J. Am. Chem. Soc. 1996, 118, 6317-6318.

(30) Geuenich, D.; Hess, K.; Kohler, F.; Herges, R. Anisotropy of the induced current density (ACID), a general method to quantify and visualize electronic delocalization. Chem. Rev. 2005, 105, 37583772.

(31) Baryshnikov, G. V.; Valiev, R. R.; Karaush, N. N.; Minaev, B. F. Aromaticity of the planar hetero[8]circulenes and their doubly charged ions: NICS and GIMIC characterization. Phys. Chem. Chem. Phys. 2014, 16, 15367-15374. 